\title{
Genetic Characterization of Myoid Hamartoma of the Breast
}

\author{
IOANNIS PANAGOPOULOS ${ }^{1}$, LUDMILA GORUNOVA ${ }^{1}$, \\ HEGE KILEN ANDERSEN ${ }^{1}$, THOMAS DAHL PEDERSEN ${ }^{2}$, JON LØMO ${ }^{2}$, \\ MARIUS LUND-IVERSEN ${ }^{2}$, FRANCESCA MICCI ${ }^{1}$ and SVERRE HEIM ${ }^{1,3}$ \\ ${ }^{1}$ Section for Cancer Cytogenetics, Institute for Cancer Genetics and Informatics, \\ The Norwegian Radium Hospital, Oslo University Hospital, Oslo, Norway; \\ ${ }^{2}$ Department of Pathology, Oslo University Hospital, Oslo, Norway; \\ ${ }^{3}$ Institute of Clinical Medicine, Faculty of Medicine, University of Oslo, Oslo, Norway
}

\begin{abstract}
Background/Aim: Myoid hamartoma of the breast is a very rare benign lesion of which only a few cases have been reported. The pathogenesis is unknown and nothing is known about its genetic constitution. We report here the genetic characterization of a myoid hamartoma of the breast. Materials and Methods: Cytogenetic, fluorescence in situ hybridization (FISH), RNA sequencing, reverse transcription polymerase chain reaction (RT-PCR), and Sanger sequencing analyses were performed on a myoid hamartoma of the breast. Results: G-Banding analysis of short-term cultured tumor cells yielded the karyotype 46,XX,t(5;12)(p13;q14)[6]/46,XX[4]. FISH showed rearrangement of the high mobility group AThook 2 (HMGA2) gene. RNA sequencing detected fusion of HMGA2 (12q14) with a sequence from 5p13. RT-PCR together with Sanger sequencing verified the HMGA2-fusion transcript. Conclusion: Myoid hamartoma of the breast may be pathogenetically related to benign connective tissue tumors with HMGA2 rearrangements, such as pulmonary hamartomas, lipomas, myolipomas, and leiomyomas.
\end{abstract}

Hamartoma is a benign tumor made up of an abnormal focal overgrowth of cells and tissues normally present in that part of the body. It can develop in various organs including the lungs, skin, hypothalamus and breast (1-4). The term 'mammary

This article is freely accessible online.

Correspondence to: Ioannis Panagopoulos, Section for Cancer Cytogenetics, Institute for Cancer Genetics and Informatics, The Norwegian Radium Hospital, Oslo University Hospital, Montebello, PO Box 4954 Nydalen, NO-0424 Oslo, Norway. Tel: +47 22782362, email: ioannis.panagopoulos@rr-research.no

Key Words: Myoid hamartoma of the breast, chromosome translocation, cytogenetics, HMGA2 rearrangement, fluorescence in situ hybridization, RNA sequencing, reverse transcription polymerase chain reaction, Sanger sequencing. hamartoma' was first used by Arrigoni et al. (5) to describe a well-circumscribed breast lesion with varying amounts of benign epithelial elements, fibrous tissue, and fat (5). Myoid (muscular) hamartoma of the breast was described 2 years later by Davies and Riddell (6) as a subtype of breast hamartoma characterized by the presence of smooth muscle cells. It is a very rare benign lesion of which only few cases have been reported (7-22). The pathogenesis is unknown and nothing is known about their genetic constitution. We report here the genetic characterization of a myoid hamartoma of the breast.

\section{Materials and Methods}

Ethics statement. The study was approved by the Regional Ethics Committee (Regional komité for medisinsk forskningsetikk Sør-Øst, Norge, http://helseforskning .etikkom.no). Written informed consent to publication of the case details was obtained from the patient. The Ethics Committee's approval included a review of the consent procedure. All patient information has been de-identified.

Patient. Routine examination of a 44-year-old female by her general physician detected a lump in the left breast. Radiological examination revealed a well-defined tumor measuring $57 \times 31 \times 42$ $\mathrm{mm}$. Upon mammography, the lump was translucent, whereas magnetic resonance imaging and ultrasound examination of the lump gave heterogeneous signals. The diagnosis on core-needle biopsy was leiomyomatous tumor of uncertain malignant potential. A lumpectomy was performed.

Microscopic examination of the specimen showed a welldemarcated lesion without capsule, consisting of alternating areas of glandular, fat and smooth muscle tissue (Figure 1A-C). The latter component was quite prominent, displaying tightly packed bundles of smooth muscle cells showing immunohistochemical positivity for the muscle markers desmin and smooth muscle actin (Figure 1D). The glandular tissue displayed clefts in the fibrous stroma consistent with pseudoangiomatous stromal hyperplasia (Figure 1A and B). The fat tissue was pure in some areas, and scattered, single fat cells in others (Figure 1C). No atypia was seen, nor were any mitoses detected in any component. The final diagnosis was myoid hamartoma. 
$G$-Banding and karyotyping. Fresh tissue from a representative area of the tumor was analyzed cytogenetically as part of our diagnostic routine. The samples were disaggregated mechanically and enzymatically with collagenase II (Worthington, Freehold, NJ, USA). The resulting cells were cultured and harvested using standard techniques (23). Chromosomal preparations were G-banded with Wright's stain (Sigma Aldrich, St Louis, MO, USA) and examined. Metaphases were analyzed and karyograms prepared using the CytoVision computer assisted karyotyping system (Leica Biosystems, Newcastle-upon-Tyne, UK). The karyotypes were described according to the International System for Human Cytogenomic Nomenclature (24).

Fluorescence in situ hybridization (FISH). FISH analysis was performed on both interphase nuclei and metaphase plates (see below). A homemade high mobility group AT-hook 2 (HMGA2) break-apart probe was made from commercially available bacterial artificial chromosomes. The 5'-end of the probe (red signal) was constructed from a pool of clones RP11-185K16, RP11-30I11, and RP11-662G15. The 3'-end of the probe (green signal) was constructed from a pool of the clones RP118B13, RP11-745O10, and RP11-263A04. All of them map to chromosome subband $12 \mathrm{q} 14.3$ and cover the HMGA2 locus. Detailed information about the probe is given elsewhere $(25,26)$.

RNA sequencing. Total RNA was extracted from frozen $\left(-80^{\circ} \mathrm{C}\right)$ tumor tissue adjacent to that used for cytogenetic analysis and histological examination using miRNeasy Mini Kit (Qiagen Nordic, Oslo, Norway). One microgram of total RNA was sent to the Genomics Core Facility at the Norwegian Radium Hospital, Oslo University Hospital (http://genomics.no/oslo/) for high-throughput paired-end RNA-sequencing. For library preparation from total RNA, Illumina TruSeq RNA Access Library Prep kit was used according to Illumina's protocol (Illumina, San Diego, CA, USA (https://support.illumina.com/content/dam/illumina-support/ documents/documentation/chemistry_documentation/samplepreps_tr useq/truseqrnaaccess/truseq-rna-access-library-prep-guide-15049525b.pdf). Sequencing was performed on NextSeq 550 System (Illumina) and 25 million reads were generated. The software deFuse was used for detection of possible HMGA2 fusion transcripts (27).

In order to confirm the existence of an $H M G A 2$ fusion with the sequence from chromosome band 5 p13 (see below), reverse transcription (RT) polymerase chain reaction (PCR) and Sanger sequencing analyses were performed as previously described (26). The primers used were forward: HMGA2-929F1 (ACCGGTGA GCCCTCTCCTAAGAG) and reverse: 5p13R (GAAATGGGT CAGGCCTATCAGCA).

\section{Results}

G-Banding analysis yielded a karyotype with a single chromosomal abnormality: 46,XX,t(5;12)(p13;q14)[6]/46, XX[4] (Figure 2A). FISH analysis on metaphase spreads showed that the distal part of the HMGA2 probe hybridized to the p13 band of $\operatorname{der}(5)$, whereas the proximal part of the probe hybridized to the q14 band of der(12) (Figure 2B). Interphase FISH showed two normal (yellow) signals in 48 nuclei and one yellow, one red, and one green signal (i.e. splitting of the $H M G A 2$ probe) in 39 nuclei.
Using the deFuse software on the fastq files of the RNA sequencing data, a fusion of $H M G A 2$ with a sequence from chromosome band 5p13.2 was found (Figure 2C).

RT-PCR with the primer combination HMGA2929F1/5p13R amplified a 349 bp cDNA fragment (data not shown). Direct sequencing of the PCR fragment showed that it was an HMGA2-chimeric cDNA fragment (Figure 2D). The fusion point was identical to that found by analysis of the RNA sequencing data using the deFuse software. Thus, in the HMGA2-chimeric transcript, exon 3 of HMGA2 (nt 1060 in reference sequence with accession number NM_003483.4) was fused with an intragenic sequence from chromosomal band $5 \mathrm{p} 13.2$ between the genes encoding prolactin receptor (PRLR) and sperm flagellar protein 2 (SPEF2). The HMGA2truncated transcript codes for a putative protein which contains amino acid residues 1-83 of the HMGA2 protein (accession number NP_003474.1) corresponding to exons 1-3 of the gene, and nine amino acid residues from the sequence derived from 5p13 (VHSTGEKQS) (Figure 2E).

\section{Discussion}

Although there is considerable information about the acquired genetic alterations of pulmonary chondroid hamartomas, corresponding information on hamartomas from other organs and tissues is still very limited (28). As far as we are aware, cytogenetic knowledge on hamartoma of the breast is restricted to only four cases (29-31). The first two tumors had the karyotypes 47,XX,del(1)(p22) and $46, X X, t(12 ; 16)(q 15 ; q 24)(29)$. The third hamartoma had the karyotype 46,XX, add(4)(?), add(6)(q?), der(7)t(7;12)(q11;q11$12)$,der(12) (30). The breakpoint in $12 \mathrm{q}$ was found to be within the same region as are the $12 \mathrm{q}$-breakpoints often found in other benign solid tumor types such as uterine leiomyomas, lipomas, and pleomorphic salivary gland adenomas (30). Cytogenetic changes of bands 12q13-15 are a recurrent theme in benign connective tissue tumors and have been shown to lead to rearrangement/activation of HMGA2 (28). Finally, the fourth tumor had the karyotype $46, \mathrm{XX}, \mathrm{t}(1 ; 6)(\mathrm{p} 21 ; \mathrm{p} 21)$ with rearrangement of $H M G A 1$ in $6 \mathrm{p} 21(31)$.

Herein, we report for the first time genetic analysis of a myoid hamartoma of the breast. The tumor cells had $\mathrm{t}(5 ; 12)(\mathrm{p} 13 ; \mathrm{q} 14)$ as the only cytogenetic abnormality. The translocation led to rearrangement of the HMGA2 gene fusing it with a sequence from chromosome band $5 \mathrm{p} 13$. This pattern of rearrangement is similar to what happens to $H M G A 2$ in other and more common connective tissue tumors, i.e. disruption of the HMGA2 locus leaving intact exons 1-3 which encode the AT-hook domains separating them from the 3'-untranslated region of the gene (3'-UTR) (25, 32-34). The 3'-UTR of HMGA2 has been shown to regulate transcription of the gene $(35,36)$. 
A

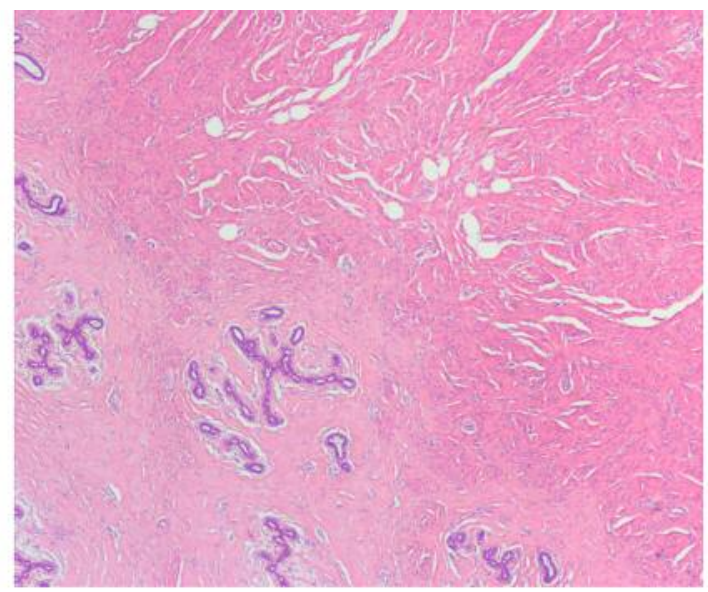

C

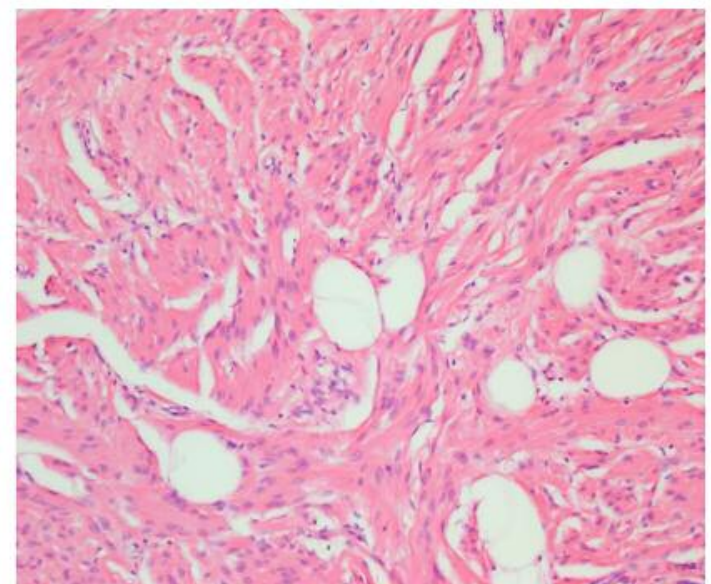

B



D



Figure 1. Microscopic examination of the myoid hamartoma of the breast. A: Hematoxylin and eosin (HE)-stained section showing the area of glandular tissue next to area of smooth muscle differentiation (upper right), x40. B: HE-stained section showing smooth muscle tissue and glandular tissue, $\times 100 . C$ : H\&E-stained section showing smooth muscle tissue and some fat cells, $\times 100$. D: Immunohistochemical examination showing expression of desmin in the smooth muscle component.

There is a plethora of data showing involvement or misexpression of the entire $H M G A 2$ or a truncated form of it in the development of various types of neoplasia $(32,37-40)$. Furthermore, mouse embryonic NIH3T3 fibroblasts are transformed in vitro by the expression of truncated HMGA2 protein carrying the three DNA-binding domains (41). Overexpression of truncated $H M G A 2$ in human myometrial cells was shown to induce leiomyoma-like tissue formation (42). Expression of full-length as well as truncated human $H M G A 2$ transcripts in transgenic mice under the control of the fatty acid binding protein $4(F a b p 4)$ gene promoter, which is a differentiated adipocyte-specific promoter, resulted in the development of neoplasms including fibroadenomas of the breast and salivary gland adenomas (43). Of note, the addition of ectopic fusion sequences was not necessary for the ability of HMGA2 to produce neoplasia (43). Recombinant HMGA2 protein was shown to increase the proliferative activity of chondrocytes in a dose-dependent manner in an in vitro system utilizing cells of porcine origin (44). Application of a synthetic peptide comprising the functional AT-hook motifs of the HMGA2 protein onto porcine hyaline cartilage chondrocytes, grown in a monolayer cell culture, showed a growth-promoting effect similar to that of wild-type HMGA2 protein (45).

The present study shows that myoid hamartoma of the breast may be genetically related to other types of benign tumor with HMGA2 rearrangements such as lipomas, myolipomas, leiomyomas, chondroid hamartomas, and hamartomas of the breast (28). The findings indicate that myoid hamartomas, similarly to other hamartomas of the breast, grow from mutated mesenchymal stem cells which are capable of differentiation into stromal cells as well as to adipocytes and smooth muscle cells $(29,30)$. 
A

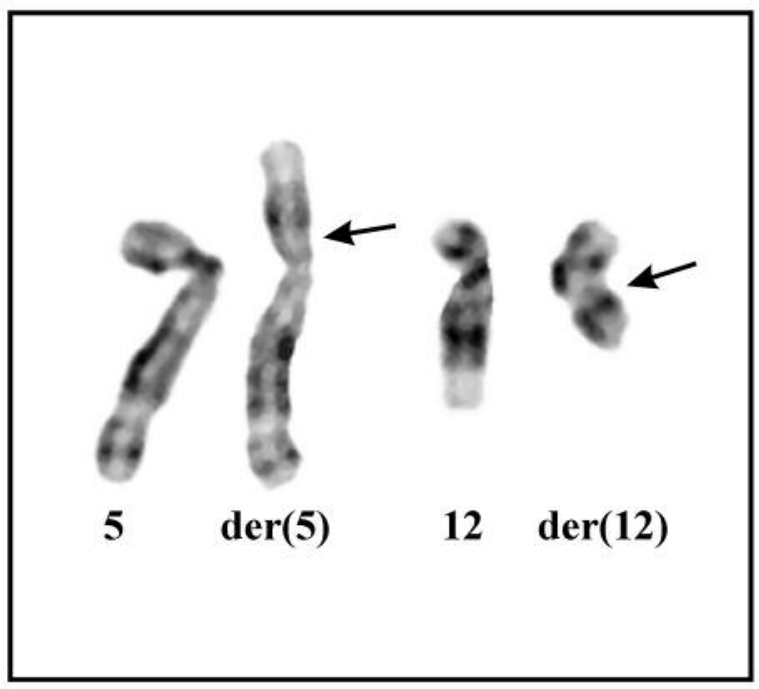

$H M G A 2$ break-apart probe

B



C

TGCAGCGGCGGTAGCGGCGGCGGGAGGCAGGATGAGCGCACGCGGTGAGGGCGCGGGGCAGCCGTCCACTTCA GCCCAGGGACAACCTGCCGCCCCAGCGCCTCAGAAGAGAGGACGCGGCCGCCCCAGGAAGCAGCAGCAAGAAC CAACCGGTGAGCCCTCTCCTAAGAGACCCAGGGGAAGACCCAAAGGCAGCAAAAACAAGAGTCCCTCTAAAGC AGCTCAAAAGAAAGCAGAAGCCACTGGAGAAAAACGGCCAAGAGGCAGACCTAGGAAATGG ITACACAGCAC TGGAGAGAAGCAGAGCTAAGGAGGTGAAGTGTCTGTCTGTCTTGCTGAAAGCAGCTGGGAGTGGGAAAAAATA GTCTTGTCCACTTTTGGCTATCTCAAGATGAACATGGAGCTCTCCAGCAGAGGAAATGTCTAGGAGGATAAGG TGACATCTATCAAGTGAACCTACTATGCGAACACATCTGCTGATAGGCCTGACCCATTTCTATCATCTGAGAA TCTCAAGTAGCTTGTCCACCAGCCACAGGTTGTTAAACATTGATGGTGGATACTGTA

\section{$H M G A 2$ exon $3 \downarrow$ Sequence from 5 p13.2}

D A.AAAC G GC CAAG AGGCA G ACC TA G GAAT G G T ACACA G C AC T G G A A GAAGAGAGCTAAG

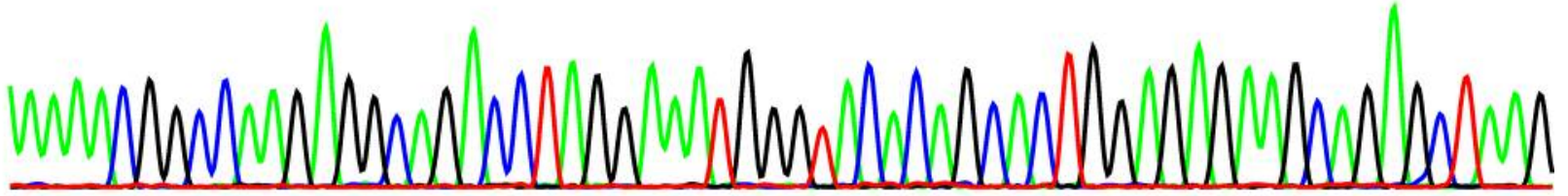
KRPRGRPRKWVHSTGEKQS

Figure 2. Genetic examination of myoid hamartoma of the breast. A: Partial karyotype showing the der(5)t(5;12)(p13;q14), $\operatorname{der}(12) t(5 ; 12)(p 13 ; q 14)$, and normal chromosomes 5 and 12. Breakpoint positions are indicated by arrows. B: Fuorescence in situ hybridization on a metaphase spread with the high mobility group AT-hook 2 (HMGA2) break-apart probe. A normal yellow signal is seen on chromosome 12, a red signal on der(12) (arrow), and a green signal on der(5) (arrow). C: HMGA2-fusion sequence obtained from the raw data after RNA sequencing using the deFuse software package. The G/G junction of HMGA2 with sequence from chromosome band $5 p 13$ is highlighted with red. The position of the forward HMGA2-929F1 and reverse 5p13R primers are highlighted with green. D: Partial sequence chromatogram of the cDNA amplified fragment showing the junction position of HMGA2 and sequence from chromosome band 5 p13 (arrow). The stop codon TAA is underlined. E: The putative protein which contains amino acid residues 1-83 of HMGA2 (accession number NP_003474.1) as well as nine amino acid residues VHSTGEKQS from the 5 p13 sequence (highlighted with yellow). 


\section{Conflicts of Interest}

The authors declare that they have no potential conflicts of interest in regard to this study.

\section{Authors' Contributions}

IP designed and supervised the research, performed molecular genetic experiments, bioinformatics analysis, and wrote the article. LG performed cytogenetic analysis and evaluated the FISH data. HKA performed FISH analysis and evaluated the FISH data. TDP performed the pathological examination. JL performed the pathological examination. ML-I performed the pathological examination. FM supervised the research. SH assisted with experimental design and writing of the article. All Authors read and approved the final article.

\section{Acknowledgements}

This work was supported by grants from Radiumhospitalets Legater.

\section{References}

1 Wick MR: Hamartomas and other tumor-like malformations of the lungs and heart. Semin Diagn Pathol 36: 2-10, 2019. PMID: 30473462. DOI: 10.1053/j.semdp.2018.11.002

2 Welsh CT: Hamartomas and choristomas in the nervous system. Semin Diagn Pathol 36: 62-70, 2019. PMID: 30473461. DOI: 10.1053/j.semdp.2018.11.006

3 Tjarks BJ, Gardner JM and Riddle ND: Hamartomas of skin and soft tissue. Semin Diagn Pathol 36: 48-61, 2019. PMID: 30573326. DOI: 10.1053/j.semdp.2018.12.001

4 Reisenbichler E and Hanley KZ: Developmental disorders and malformations of the breast. Semin Diagn Pathol 36: 11-15, 2019. PMID: 30503250. DOI: 10.1053/j.semdp.2018.11.007

5 Arrigoni MG, Dockerty MB and Judd ES: The identification and treatment of mammary hamartoma. Surg Gynecol Obstet 133: 577-582, 1971. PMID: 5096305.

6 Davies JD and Riddell RH: Muscular hamartomas of the breast. J Pathol 111: 209-211, 1973. PMID: 4128204. DOI: 10.1002/ path.1711110309

7 Huntrakoon M and Lin F: Muscular hamartoma of the breast. An electron microscopic study. Virchows Arch A Pathol Anat Histopathol 403: 307-312, 1984. PMID: 6428044.

8 Garfein CF, Aulicino MR, Leytin A, Drossman S, Hermann G and Bleiweiss IJ: Epithelioid cells in myoid hamartoma of the breast: A potential diagnostic pitfall for core biopsies. Arch Pathol Lab Med 120: 676-680, 1996. PMID: 8757475.

9 Rosser RJ: Epithelioid cells in myoid hamartoma of the breast. Arch Pathol Lab Med 121: 354-355, 1997. PMID: 9140300.

10 Murugesan JR, Joglekar S, Valerio D, Bradley S, Clark D and Jibril JA: Myoid hamartoma of the breast: case report and review of the literature. Clin Breast Cancer 7: 345-346, 2006. PMID: 17092405. DOI: 10.3816/CBC.2006.n.050

11 Stafyla V, Kotsifopoulos N, Grigoriadis K, Bakoyiannis CN, Peros G and Sakorafas GH: Myoid hamartoma of the breast: A case report and review of the literature. Breast J 13: 85-87, 2007. PMID: 17214800. DOI: 10.1111/j.1524-4741.2006.00369.x
12 Khoo JJ, Alwi RI and Abd-Rahman I: Myoid hamartoma of breast with chondroid metaplasia: A case report. Malays J Pathol 31: 77-80, 2009. PMID: 19694319.

13 Bayar S, Dusunceli E, Heper AO, Guner R, Genc V and Demirkazik A: Myoid hamartoma of the breast: A very rare entity. Breast J 16: 86-88, 2010. PMID: 19929894. DOI: 10.1111/j.1524-4741.2009.00858.x

14 Kajo K, Zubor P and Danko J: Myoid (muscular) hamartoma of the breast: case report and review of the literature. Breast Care 5: 331-334, 2010. PMID: 21779216. DOI: 10.1159/000321341

15 Ko MS, Jung WS, Cha ES and Choi HJ: A rare case of recurrent myoid hamartoma mimicking malignancy: imaging appearances. Korean J Radiol 11: 683-686, 2010. PMID: 21076595. DOI: 10.3348/kjr.2010.11.6.683

16 Mizuta N, Sakaguchi K, Mizuta M, Imai A, Nakatsukasa K, Morita M, Soshi M, Goto M, Yasukawa S, Konishi E and Taguchi T: Myoid hamartoma of the breast that proved difficult to diagnose: A case report. World J Surg Oncol 10: 12, 2012. PMID: 22248347. DOI: 10.1186/1477-7819-10-12

17 Nasit JG, Parikh B, Trivedi P and Shah M: Myoid (muscular) hamartoma of the breast with chondroid metaplasia. Indian J Pathol Microbiol 55: 121-122, 2012. PMID: 22499322. DOI: 10.4103/0377-4929.94883

18 Schafer FK, Biernath-Wuepping J, Eckmann-Scholz C, Order BM, Mathiak M, Hilpert F, Strauss A, Jonat W and Schafer PJ: Rare benign entities of the breast - myoid hamartoma and capillary hemangioma. Geburtshilfe Frauenheilkd 72: 412-418, 2012. PMID: 25298546. DOI: 10.1055/s-0031-1298571

19 Nangia A, Patiri K, Pujani M and Sehgal S: Bilateral myoid hamartoma of breast: An exceptionally rare lesion. Breast Dis 34: 77-80, 2013. PMID: 23963200. DOI: 10.3233/BD-130355

20 Makiguchi T, Horiguchi J, Nagaoka R, Yokoo S, Terashi H, Oyama $\mathrm{T}$ and Takeyoshi I: Huge myoid hamartoma of the breast treated with reduction mammaplasty: Report of a case. Surg Today 44: 2369-2373, 2014. PMID: 24468741. DOI: 10.1007/s00595-0140833-4

$21 \mathrm{Su}$ CC, Chen CJ, Kuo SJ and Chen DR: Myoid hamartoma of the breast with focal chondromyoxid metaplasia and pseudoangiomatous stromal hyperplasia: A case report. Oncol Lett 9: 1787-1789, 2015. PMID: 25789043. DOI: 10.3892/ol.2015.2892

22 Felipe Lima J, Sirkin W and Hanna WM: Myoid hamartoma of the breast with symplastic changes. Breast J 22: 583-584, 2016. PMID: 27346672. DOI: $10.1111 /$ tbj.12642

23 Mandahl N: Methods in solid tumour cytogenetics. In: Human Cytogenetics: Malignancy and Acquired Abnormalities. Rooney DE (ed.). New York: Oxford University Press, pp. 165-203, 2001.

24 McGowan-Jordan J, Simons A and Schmid M: ISCN 2016: An International System for Human Cytogenomic Nomenclature. Basel: Karger, 2016.

25 Panagopoulos I, Bjerkehagen B, Gorunova L, Taksdal I and Heim S: Rearrangement of chromosome bands 12q14 15 causing HMGA2-SOX5 gene fusion and HMGA2 expression in extraskeletal osteochondroma. Oncol Rep 34: 577-584, 2015. PMID: 26043835. DOI: 10.3892/or.2015.4035

26 Panagopoulos I, Gorunova L, Brunetti M, Agostini A, Andersen HK, Lobmaier I, Bjerkehagen B and Heim S: Genetic heterogeneity in leiomyomas of deep soft tissue. Oncotarget 8: 48769-48781, 2017. PMID: 28591699. DOI: 10.18632/oncotarget.17953

27 McPherson A, Hormozdiari F, Zayed A, Giuliany R, Ha G, Sun MG, Griffith M, Heravi Moussavi A, Senz J, Melnyk N, Pacheco 
M, Marra MA, Hirst M, Nielsen TO, Sahinalp SC, Huntsman D and Shah SP: deFuse: An algorithm for gene fusion discovery in tumor RNA-Seq data. PLoS Comput Biol 7: e1001138, 2011. PMID: 21625565. DOI: 10.1371/journal.pcbi.1001138

28 Heim S and Mitelman F: Cancer Cytogenetics: Chromosomal and Molecular Genetic Abberations of Tumor Cells: WileyBlackwell, 2015.

29 Dietrich CU, Pandis N, Andersen JA and Heim S: Chromosome abnormalities in adenolipomas of the breast: Karyotypic evidence that the mesenchymal component constitutes the neoplastic parenchyma. Cancer Genet Cytogenet 72: 146-150, 1994. PMID: 8143274.

30 Rohen C, Caselitz J, Stern C, Wanschura S, Schoenmakers EF, Van de Ven WJ, Bartnitzke S and Bullerdiek J: A hamartoma of the breast with an aberration of $12 \mathrm{q}$ mapped to the MAR region by fluorescence in situ hybridization. Cancer Genet Cytogenet 84: 82-84, 1995. PMID: 7497449.

31 Dal Cin P, Wanschura S, Christiaens MR, Van den Berghe I, Moerman P, Polito P, Kazmierczak B, Bullerdiek J and Van den Berghe H: Hamartoma of the breast with involvement of $6 \mathrm{p} 21$ and rearrangement of HMGIY. Genes Chromosomes Cancer 20: 90-92, 1997. PMID: 9290959.

32 Cleynen I and Van de Ven WJ: The HMGA proteins: a myriad of functions (Review). Int J Oncol 32: 289-305, 2008. PMID: 18202751 .

33 Nilsson M, Mertens F, Hoglund M, Mandahl $\mathrm{N}$ and Panagopoulos I: Truncation and fusion of $H M G A 2$ in lipomas with rearrangements of 5q32-->q33 and 12q14-->q15. Cytogenet Genome Res 112: 60-66, 2006. PMID: 16276091. DOI: $10.1159 / 000087514$

34 Agostini A, Gorunova L, Bjerkehagen B, Lobmaier I, Heim S and Panagopoulos I: Molecular characterization of the $\mathrm{t}(4 ; 12)$ (q27 28; 14 15) chromosomal rearrangement in lipoma. Oncol Lett 12: 1701-1704, 2016. PMID: 27588119. DOI: 10.3892/ol.2016.4834

35 Borrmann L, Wilkening $\mathrm{S}$ and Bullerdiek J: The expression of HMGA genes is regulated by their 3'UTR. Oncogene 20: 45374541, 2001. PMID: 11494149. DOI: 10.1038/sj.onc.1204577

36 Kristjansdottir K, Fogarty EA and Grimson A: Systematic analysis of the Hmga2 3' UTR identifies many independent regulatory sequences and a novel interaction between distal sites. RNA 21: 1346-1360, 2015. PMID: 25999317. DOI: 10.1261/rna. 051177.115
37 Fusco A and Fedele M: Roles of HMGA proteins in cancer. Nat Rev Cancer 7: 899-910, 2007. PMID: 18004397. DOI: $10.1038 / \mathrm{nrc} 2271$

38 Fedele $\mathrm{M}$ and Fusco A: HMGA and cancer. Biochim Biophys Acta 1799: 48-54, 2010. PMID: 20123067. DOI: 10.1016/ j.bbagrm.2009.11.007

39 Peluso S and Chiappetta G: High-mobility group A (HMGA) proteins and breast cancer. Breast Care 5: 81-85, 2010. PMID: 20847819. DOI: $10.1159 / 000297717$

40 D'Angelo D, Mussnich P, Arra C, Battista S and Fusco A: Critical role of HMGA proteins in cancer cell chemoresistance. J Mol Med 95: 353-360, 2017. PMID: 28293697. DOI: 10.1007/s00109-017-1520-x

41 Fedele M, Berlingieri MT, Scala S, Chiariotti L, Viglietto G, Rippel V, Bullerdiek J, Santoro M and Fusco A: Truncated and chimeric HMGI-C genes induce neoplastic transformation of NIH3T3 murine fibroblasts. Oncogene 17: 413-418, 1998. PMID: 9696033. DOI: 10.1038/sj.onc.1201952

42 Mas A, Cervello I, Fernandez-Alvarez A, Faus A, Diaz A, Burgues O, Casado $\mathrm{M}$ and Simon C: Overexpression of the truncated form of high mobility group A proteins (HMGA2) in human myometrial cells induces leiomyoma-like tissue formation. Mol Hum Reprod 21: 330-338, 2015. PMID: 25542836. DOI: 10.1093/molehr/gau 114

43 Zaidi MR, Okada Y and Chada KK: Misexpression of full-length HMGA2 induces benign mesenchymal tumors in mice. Cancer Res 66: 7453-7459, 2006. PMID: 16885341. DOI: 10.1158/ 0008-5472.CAN-06-0931

44 Richter A, Hauschild G, Murua Escobar H, Nolte I and Bullerdiek J: Application of high-mobility-group-A proteins increases the proliferative activity of chondrocytes in vitro. Tissue Eng Part A 15: 473-477, 2009. PMID: 18721076. DOI: 10.1089/ten.tea.2007.0308

45 Richter A, Lubbing M, Frank HG, Nolte I, Bullerdiek JC and von Ahsen I: High-mobility group protein HMGA2-derived fragments stimulate the proliferation of chondrocytes and adipose tissue-derived stem cells. Eur Cells Mater 21: 355-363, 2011. PMID: 21484705.
Received August 31, 2019

Revised September 23, 2019 Accepted September 26, 2019 